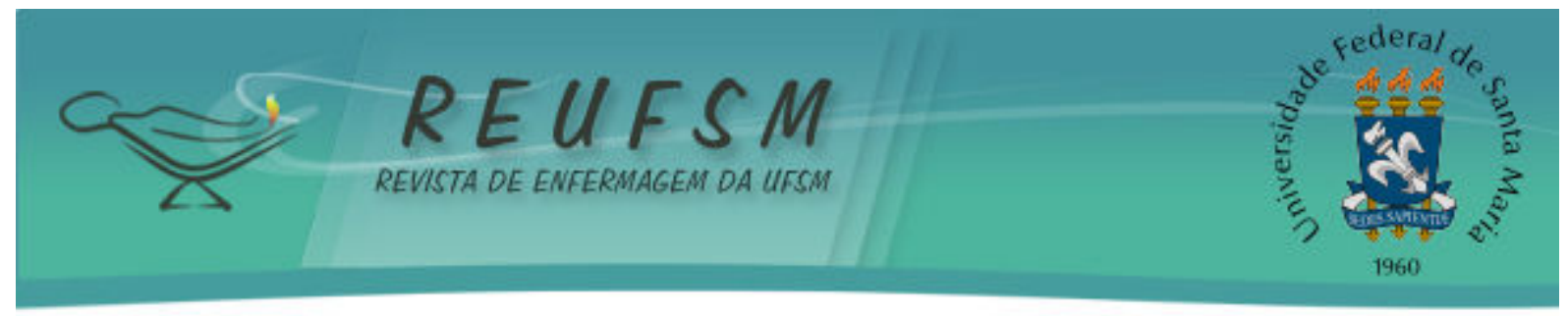

ARTIGO ORIGINAL

\title{
PERCEPÇÃO DE ENFERMEIROS-LÍDERES SOBRE O GERENCIAMENTO DE CONFLITOS NO AMBIENTE HOSPITALAR
}

\author{
PERCEPTION OF NURSE LEADERS ABOUT MANAGING CONFLICTS IN THE HOSPITAL \\ ENVIRONMENT
} PERCEPCIÓN DE ENFERMEROS-LÍDERES ACERCA DE LA GESTIÓN DE CONFLICTOS EN EL
AMBIENTE HOSPITALARIO

\author{
Simone Coelho Amestoy ${ }^{1}$ \\ Rejane Santos Peixoto ${ }^{2}$ \\ Raquel Pötter Garcia ${ }^{3}$ \\ Bianca Pozza dos Santos ${ }^{4}$ \\ Camila Neves da Silva ${ }^{5}$ \\ Diego Duro Braga ${ }^{6}$
}

Doi: $10.5902 / 2179769218167$

RESUMO: Objetivo: conhecer a percepção de enfermeiros-líderes sobre o gerenciamento de conflitos no ambiente hospitalar. Método: pesquisa qualitativa e descritiva, em que participaram dez enfermeiros que trabalhavam em um hospital da região sul do Brasil. A coleta de dados foi realizada nos meses de outubro a novembro de 2014, por meio de entrevistas semiestruturadas e analisadas conforme Proposta Operativa. Resultados: os conflitos de relacionamento foram os mais relatados pelos participantes, sendo causados pela falta de continuidade das atividades desempenhadas pela equipe de enfermagem e excesso de trabalho. 0 diálogo e a realização de reuniões foram as principais estratégias adotadas para minimizá-los. Considerações finais: para ser resolutivo, o gerenciamento de conflitos carece de maiores investimentos no ensino, durante a graduação.

Descritores: Enfermagem; Liderança; Serviços hospitalares.

ABSTRACT: Aim: to know the perception of nurse leaders about managing conflicts in the hospital enviroment. Method: qualitative and descriptive research, which was attended by ten nurses who worked in a hospital in southern Brazil. The data collection was conducted from October to November 2014 through semistructured interviews and analyzed according to the Operative Proposal. Results: the relationship conflicts were the most experienced by the participants. Those conflicts were caused by the lack of continuity of the activities performed by the nursing staff and by overwork. Dialogue and meetings were mentioned as the main strategies adopted to minimize them. Final thoughts: to be competent, the conflict management requires greater investment in education, during the graduation.

Descriptors: Nursing; Leadership; Hospital Services.

\footnotetext{
1 Enfermeira, Doutora em Enfermagem, Professora Adjunto da Faculdade de Enfermagem da Universidade Federal de Pelotas em exercício provisório na Escola de Enfermagem da Universidade Federal da Bahia, Salvador, Bahia, Brasil. E-mail: simoneamestoy@hotmail.com

2 Enfermeira, Egressa da Faculdade de Enfermagem da Universidade Federal de Pelotas, Pelotas, Rio Grande do Sul, Brasil. E-mail: rejane.peixoto@hotmail.com

${ }^{3}$ Enfermeira, Doutoranda em Enfermagem pelo Programa de Pós-graduação da Faculdade de Enfermagem da Universidade Federal de Pelotas, Professora da Universidade do Pampa-Campus Uruguaiana, Uruguaiana, Rio Grande do Sul, Brasil. E-mail: raquelpottergarcia@gmail.com

${ }^{4}$ Enfermeira, Doutoranda do Programa de Pós-Graduação em Enfermagem da Universidade Federal de Pelotas, Rio Grande do Sul, Brasil. E-mail: bi.santos@bol.com.br

${ }^{5}$ Enfermeira, Egressa da Faculdade de Enfermagem da Universidade Federal de Pelotas, Pelotas, Rio Grande do Sul, Brasil. E-mail: neves.mi@hotmail.com

${ }^{6}$ Enfermeiro, Egresso da Faculdade de Enfermagem da Universidade Federal de Pelotas, Pelotas, Rio Grande do Sul, Brasil. E-mail: diegodurobraga@hotmail.com
} 


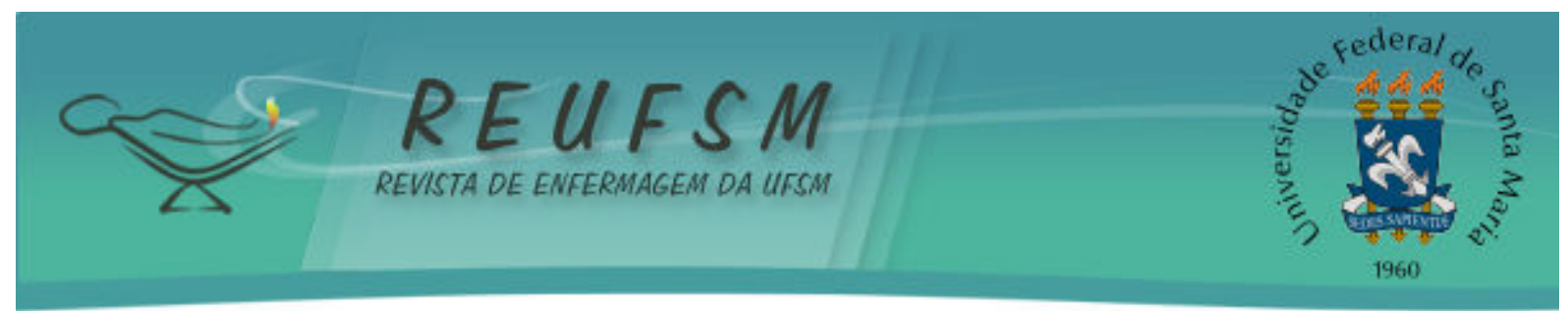

RESUMEN: Objetivo: conocer la percepción de enfermeros-líderes sobre la gestión de conflictos en el hospital. Método: investigación cualitativa y descriptiva, en que participaron diez enfermeros trabajadores de un hospital del sur de Brasil. La recolección de datos ocurrió entre octubre/noviembre de 2014, a través de entrevistas semiestructuradas analizadas según la Propuesta Operativa. Resultados: los conflictos de relacionamiento fueron los más vivenciados pelos participantes siendo causados por la falta de continuidad de las actividades realizadas por el equipo de enfermería y el exceso de trabajo. Diálogo y reuniones fueron las principales estrategias adoptadas para minimizarlos. Consideraciones finales: para ser resolutivo, el gerenciamiento de conflictos necesita de mayores investimentos en la educación, durante la graduación.

Descriptores: Enfermería; Liderazgo; Servicios hospitalarios.

\section{INTRODUÇÃO}

No cotidiano de trabalho do enfermeiro, destaca-se sua responsabilidade quanto ao gerenciamento do cuidado e da equipe de enfermagem. Para tanto, o profissional necessita atuar com discernimento e sabedoria, integrado com os demais serviços, em uma relação de troca e ajuda mútua, envolvendo os diversos profissionais presentes no sistema de cuidado. ${ }^{1}$

Diante do processo de trabalho da enfermagem é necessário que os enfermeiros tenham conhecimento sobre a importância da elaboração de planos, de projetos e de metas a serem alcançadas na instituição em que exercem suas atividades, além de conhecer as relações interpessoais estabelecidas com os integrantes da equipe de enfermagem e demais profissionais da saúde. Também é imprescindível que procurem compreender cada situação, intervindo expressivamente no cuidado proporcionado às pessoas. $^{2}$

Além disso, no cenário contemporâneo da saúde, o enfermeiro necessita desenvolver habilidades relacionais, como a liderança. No que se refere ao conceito de liderança, esta pode ser compreendida como a habilidade do enfermeiro-líder de influenciar sua equipe, de forma que juntos possam alcançar objetivos compartilhados, tendo como finalidade central, o atendimento das necessidades de saúde dos pacientes e de suas famílias. ${ }^{3} 0$ enfermeiro-líder caracteriza-se como o profissional capaz de influenciar de forma construtiva os demais integrantes da equipe de enfermagem e saúde, com o intuito de qualificar o gerenciamento do cuidado e de fortalecer as relações interpessoais no trabalho. ${ }^{3}$

Destaca-se que os enfermeiros podem atuar como facilitadores na construção de relações de trabalho humanizadas, por meio da adoção de estratégias que estimulem a autonomia, o protagonismo e a corresponsabilidade dos sujeitos envolvidos no processo de produção de saúde, por meio de novos espaços de encontro para a troca e a construção de saberes. ${ }^{4}$

Perante as modificações presentes no mundo, tais como a globalização, ampliação do aparato tecnológico e envelhecimento populacional, existe a necessidade de uma visão ampliada do cuidado, para oferecer assistência eficiente e de qualidade, com vistas a suprir as necessidades de saúde da população. ${ }^{5}$ Nesse contexto, a liderança se torna um instrumento de trabalho imprescindível para o enfermeiro, pois representa uma habilidade relacional, em que o líder exerce influência sobre seus colaboradores, por meio do estabelecimento de laços de confiança, com o intuito de facilitar o gerenciamento do cuidado e da equipe de enfermagem. ${ }^{3}$

A harmonia é uma das consequências do convívio amigável do grupo, porém, situações desagradáveis podem ser inevitáveis. ${ }^{6} 0$ conflito caracteriza-se por ser uma 


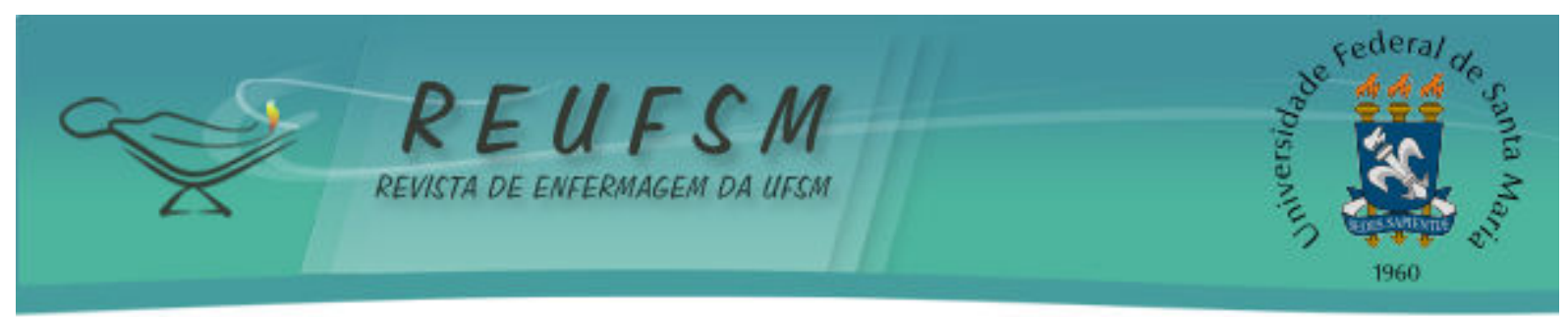

situação indesejada, revelada pela incompatibilidade, discordância ou desavença entre pessoas e pode causar um efeito construtivo ou destrutivo, dependendo da maneira como é administrado. ${ }^{7}$ Podem ser classificados como: conflito de tarefa, relacionado ao complexo de regras ou normas e aos objetivos da atividade laboral; de relacionamento, vinculado às condições das relações interpessoais e de processo, que se relaciona à maneira como a atividade laboral é executada. ${ }^{8}$ Reconhecer sua origem torna-se essencial, pois norteia a escolha de estratégias que possam colaborar com sua a resolução.

A produção científica sobre o assunto tem avançado, a fim de auxiliar o enfermeiro a gerenciar situações problemáticas nos serviços de saúde. Pode-se destacar estudo realizado com médicos de setores clínicos e cirúrgicos de um Hospital Universitário de Goiás, que objetivou identificar a existência de conflitos entre profissionais médicos e enfermeiros, bem como seus possíveis fatores determinantes e causadores. ${ }^{9}$ Outra investigação realizada com enfermeiros de instituições hospitalares de uma cidade no interior do Rio Grande do Sul, analisou como os conflitos se manifestam nas relações interpessoais e a magnitude que esses assumem no âmbito do exercício gerencial diante do universo de organização de saúde do tipo hospitalar. ${ }^{7}$

Em vista desses achados na literatura, a proposta para a realização deste estudo partiu do fato de que o enfermeiro sofre direta ou indiretamente com a existência de conflitos. A partir do exposto, elaborou-se a seguinte questão de pesquisa: Qual a percepção de enfermeiros-líderes sobre o gerenciamento de conflitos no ambiente hospitalar? Para tanto, objetivou-se conhecer a percepção de enfermeiros-líderes sobre o gerenciamento de conflitos no ambiente hospitalar.

\section{MÉTODO}

Este estudo caracterizou-se por ser qualitativo, do tipo descritivo e integra um macroprojeto denominado: 0 exercício da liderança na enfermagem: um estudo na rede hospitalar de Pelotas/RS. Foi realizado em um hospital público de médio porte, localizado na Região Sul do Brasil, vinculado à Universidade Federal de Pelotas. É destinado a atender usuários do Sistema Único de Saúde, sendo referência para 22 municípios da região.

Cabe informar que no período da coleta de dados atuavam no hospital 58 enfermeiros, destes, dez participaram da pesquisa. Adotou-se como critério de inclusão: ser enfermeiro e trabalhar no hospital, no mínimo, há seis meses. Optou-se por estabelecer este período mínimo de atuação, para que o enfermeiro pudesse estar mais familiarizado com a equipe e com as rotinas da instituição. Foram excluídos os enfermeiros afastados do trabalho, independente do motivo (férias, licença maternidade ou doença). A definição do número de participantes ocorreu por inclusão progressiva. A inclusão dos participantes foi definida pelo critério de saturação, ou seja, quando a opinião dos enfermeiros sobre o assunto começou a ter regularidade de apresentação, além de responder ao objetivo do estudo. ${ }^{10}$

A coleta de dados foi realizada por meio de entrevista semiestruturada, que ocorreu no próprio local de trabalho dos participantes, de forma individual e em ambiente privativo, com data e hora pré-estabelecidas, conforme contato prévio. 0 tempo médio de duração das entrevistas foi de, aproximadamente, 50 minutos. Primeiramente, foram coletados dados de caracterização dos participantes, que abrangiam idade, tempo de formação, de experiência profissional e de trabalho na instituição. Os enfermeiros foram questionados sobre o gerenciamento de conflitos e as estratégias adotadas para gerenciálos. 


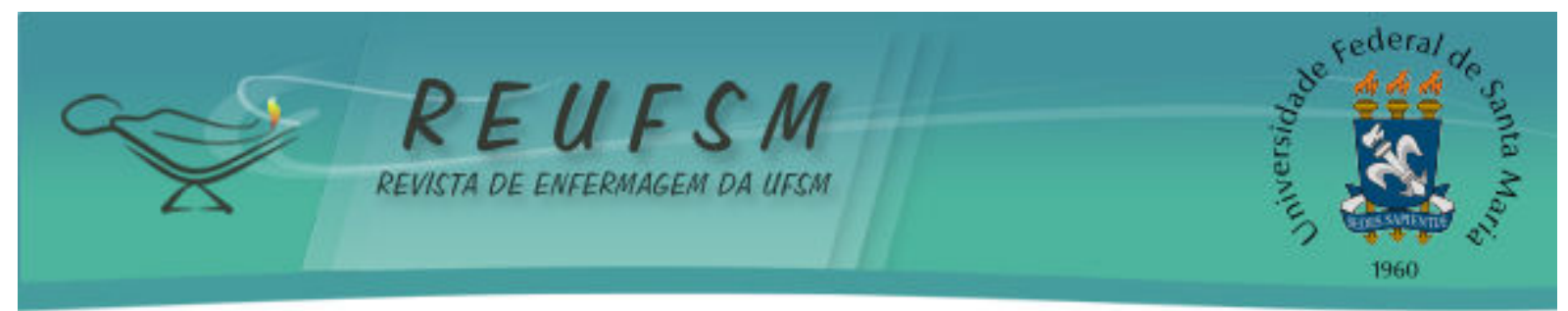

Para a análise dos dados, foi utilizada a Proposta Operativa, na qual o conteúdo foi estruturado e organizado a partir de duas etapas: a fase exploratória da investigação constituiu o marco-teórico fundamental para a análise; e a interpretativa utilizou dos relatos dos participantes para dar sentido, lógica e projeção, além de buscar a compreensão e a agregação das respostas, fazendo uma interligação dos objetivos da pesquisa com a literatura. ${ }^{11}$

O estudo possui a aprovação do Comitê de Ética em Pesquisa da Santa Casa de Misericórdia de Pelotas, conforme protocolo $n^{\circ} 200 / 2013$. Foram respeitados os preceitos da Resolução 466/2012 do Conselho Nacional de Saúde, que atende as diretrizes e normas regulamentadoras de pesquisas envolvendo seres humanos. ${ }^{12}$ Com a finalidade de preservar o anonimato, os participantes foram identificados pela letra $E$, seguidos da ordem numérica em que foram entrevistados (E1, E2... E10).

\section{RESULTADOS E DISCUSSÃO}

Os dez enfermeiros entrevistados no hospital possuíam idades entre 25 e 52 anos. Quanto à formação, sete apresentavam pós-graduação e três, graduação. 0 tempo de experiência profissional variou de seis meses a 29 anos e o tempo de trabalho na instituição, entre seis meses a 20 anos. A apresentação dos resultados está organizada em duas categorias: percepção dos enfermeiros-líderes sobre o gerenciamento de conflitos e tipos de conflitos e suas estratégias de enfrentamento.

\section{Percepção dos enfermeiros-líderes sobre o gerenciamento de conflitos}

Identificou-se que os participantes perceberam o gerenciamento de conflitos como uma atividade constante em seu cotidiano. Esse fato pode ser observado nos seguintes depoimentos:

eu acho que gerenciar conflito, a gente faz isso todos os dias. $O$ enfermeiro está ali por isso, para resolver o problema da unidade, para resolver o conflito, para tornar o serviço mais prático, mais fácil. (E1)

acho que o gerenciamento de conflitos é uma das atribuições do enfermeiro-líder, estar capacitado para conseguir fazer o grupo crescer dentro daquele conflito. A princípio, solucionar o problema ou buscar uma solução para o problema. (E5)

Nesses depoimentos, nota-se que o entrevistado E1 considera que o gerenciamento de conflitos é diário, e está presente constantemente no processo de trabalho. Já para E5, o gerenciamento de conflitos consistia em uma das atribuições do enfermeiro, para tanto esse profissional precisa estar capacitado para poder gerenciá-lo.

As preocupações com os conflitos, na enfermagem, estão relacionadas à possibilidade desses fenômenos interferirem na assistência e na qualidade do cuidado ao paciente. ${ }^{13}$ Dentro do processo de trabalho, entre outras atribuições nas instituições de saúde, é de responsabilidade do enfermeiro liderar e gerenciar os serviços de enfermagem, dispondo-se a enfrentar problemas, com a finalidade de disponibilizar uma assistência com qualidade ao paciente e seus familiares. ${ }^{14}$

Cabe destacar que a liderança é uma competência profissional do enfermeiro, assim como salientou o entrevistado $\mathrm{E} 5$, por estar relacionada ao gerenciamento de 


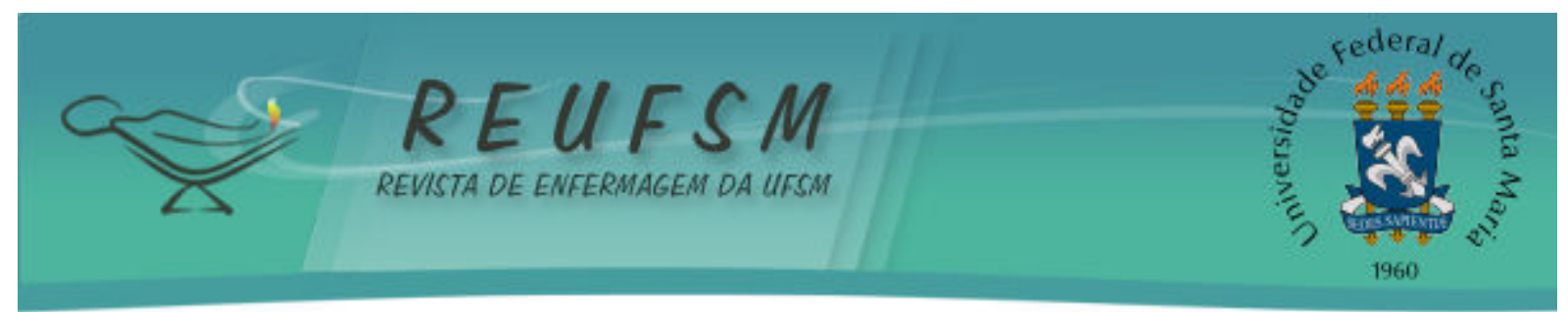

conflitos. Por outro lado, é possível também perceber, nos resultados, que os enfermeiros entenderam a liderança como a capacidade do líder de trabalhar em equipe, por meio do estabelecimento de relações horizontais, pautadas no respeito e no conhecimento. Esse argumento pode ser evidenciado por meio dos comentários dos participantes.

Liderança é representar essa equipe frente a qualquer coisa e defender essa equipe, liderar de uma forma diferenciada, fazer parte dessa equipe para que tenhas respeito. O líder tem muito mais do que dever de fazer isso, porque em prol de um melhor trabalho, de uma melhor atuação da equipe. (E2)

Liderança, eu acho que é a gente organizar o grupo que vai se trabalhar. É trabalhar junto e conseguir da melhor maneira que se trabalhe em conjunto. (E9)

Observa-se, nesses depoimentos, a definição da palavra liderança por parte dos entrevistados. A essência dos significados trazidos por E2 e E9 compreende a forma de representar a equipe em que estavam vinculados e a organização do grupo de trabalho.

Nesse sentido, a liderança pode ser conceituada de diferentes formas, desde que seja compreendida e desenvolvida para influenciar as pessoas em suas atividades de modo ético-profissional, a trabalhar com competência e habilidade, com a finalidade de alcançar metas. ${ }^{15} \mathrm{O}$ trabalho em equipe é citado pelos participantes como base fundamental para o cuidado em enfermagem, sendo um objetivo almejado pelo enfermeiro, enquanto líder.

Assim, as práticas individualistas, fragmentadas e alienadas, são multiplicadas quando o trabalho em equipe é inexistente dentro de um serviço de saúde. Essa postura imprópria dos profissionais pode repercutir diretamente no cuidado aos pacientes. Evitar tais práticas é de responsabilidade do enfermeiro, sendo que legalmente esse tem a competência para gerenciar a equipe de enfermagem durante a realização de suas tarefas. $^{3}$

Ainda, por meio dos depoimentos dos participantes, foi possível identificar dificuldades no gerenciamento dos conflitos e liderança, relacionados à formação acadêmica. Destaca-se que estas dificuldades estavam associadas a fragilidades no ensino oferecido na graduação, conforme o entendimento dos enfermeiros, que se sentiam despreparados para liderar e resolver situações conflitantes em sua prática.

Eu acho que a gente não é preparada para liderar e gerenciar conflito na faculdade. Tu vai trabalhar no primeiro emprego, primeira vez tu ficas meio perdida. Acho que isso é uma coisa que, na realidade, a faculdade não te prepara. (E4)

Ao me formar, eu não me senti preparada para gerenciar conflito. Eu acho que a gente vai aprendendo com o tempo, conforme a gente vai passando, a gente vai aprendendo, porque eu não me senti preparada para nada. Eu me formei, eu assumi aqui [no hospital], eu praticamente não sabia nada e fui pegando aqui. (E10)

Tanto E4 quanto E10 afirmaram a deficiência de preparo acadêmico, para o gerenciamento de conflitos nas atividades profissionais. Torna-se relevante mencionar que esta competência irá se efetivar mediante o exercício profissional. As experiências oferecidas pela academia podem auxiliar no preparo do estudante para gerenciar situações 


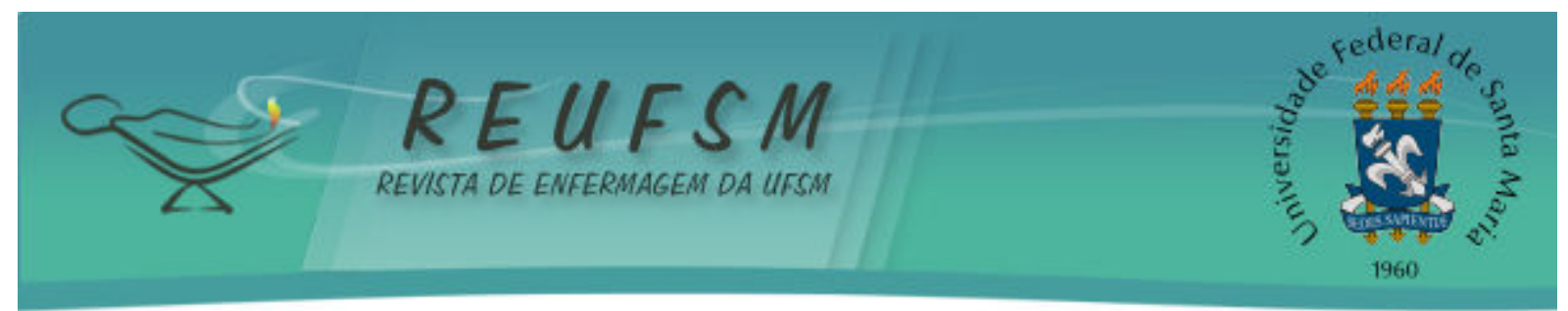

conflitantes. No entanto, convém destacar a importância de articular a teoria com as vivências práticas, com vistas a facilitar o processo de trabalho dos enfermeiros inseridos nos serviços de saúde.

Os profissionais recém-formados podem ter dificuldades para relacionar os conhecimentos obtidos na academia com a prática. ${ }^{16}$ No contexto atual, existe uma preocupação dos docentes de enfermagem quanto à formação de enfermeiros-líderes, visto que se necessita, cada vez mais, de profissionais que tenham competências técnicocientíficas e sejam capazes de exercer o gerenciamento do cuidado e da equipe de enfermagem, fazendo o uso do diálogo, da ética e da humanização. ${ }^{17}$

Para gerenciar e prestar assistência, o enfermeiro-líder necessita estar apto e qualificado para desenvolver determinadas competências e habilidades, ou seja, ampliar sua capacidade de comunicação, de escuta, de observação, de senso crítico, de negociação e de sensibilidade para analisar as pessoas, além do contexto em que está inserido. ${ }^{18}$ Essas habilidades podem ser desenvolvidas ao longo da graduação e aprimoradas de modo permanente pelo profissional.

Os enfermeiros, geralmente, trabalham em um contexto de alta pressão, de incertezas e de mudanças rápidas, incluindo os desafios diários vivenciados na prática profissional. Com o intuito de garantir o desenvolvimento de habilidades e de capacidades necessárias para execer a liderança e gerenciar conflitos, esses profisisonais precisavam ter acesso fácil a educação por meio de programas educacionais contemporâneos de alta qualidade e, de preferência, baseados em evidências. Essas ferramentas podem colaborar na capacitação dos enfermeiros tanto relacionado à clínica como aos aspectos gerenciais. ${ }^{8}$

No entanto, o contexto nacional ainda carece de investimentos quanto a formação de enfermeiros-líderes e o desenvolvimento das competências gerencias, mas esse movimento já vem acontecendo nas instituições de ensino superior, estimulado pelas diretrizes currriculares nacionais. Também cabe aos gestores dos serviços de saúde fortalecer autonomia e apoiar o enfermeiro na tomada de decisões, com vistas a auxiliá-lo na resolução das situações conflituosas.

\section{Tipos de conflitos e suas estratégias de enfrentamento}

Os tipos de conflitos vivenciados pelos enfermeiros, bem como as estratégias para enfrentá-los, também se destacaram dentre os resultados. Observa-se, a partir dos comentários a seguir, o relato desses profissionais:

equipes relacionadas a turnos de manhã com tarde, tarde com noite, o que mais tem é uma rixa. O que ficou no turno da manhã, a tarde tem que fazer. $O$ que ficou do turno da tarde, a noite tem que fazer $e$, assim, sucessivamente. A enfermagem é uma continuidade, sempre vai ficar alguma coisa para o outro turno fazer e aí sempre fica aquela reclamaçãozinha. (E1)

o principal problema entre as equipes é a quantidade de serviço realizado por cada membro. Já trabalhei em outros hospitais [...] $e$, geralmente, o que acontece é "eu trabalhei mais que tu, tu trabalhou mais que eu". (E3)

Nesses depoimentos, destacam-se os conflitos de relacionamento como os mais presentes no cotidiano dos enfermeiros, causados pela falta de continuidade das atividades 


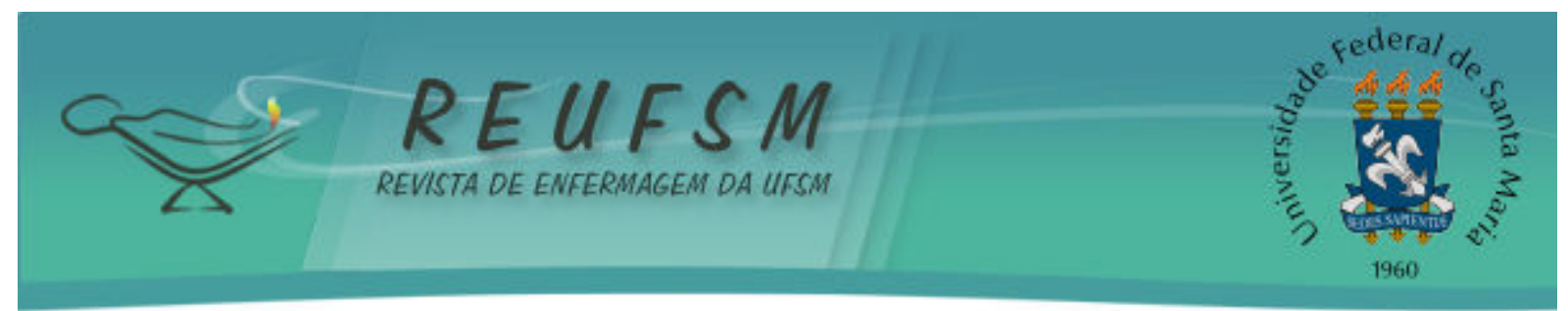

de um turno para o outro e também por excesso de trabalho. Os conflitos entre as equipes de enfermagem podem ocasionar desmotivação e insatisfação do grupo, desencadear uma redução na quantidade e na qualidade do trabalho, além de resultar no comprometimento da assistência aos pacientes. ${ }^{19}$ Nesse sentido, o trabalho necessita ser realizado em equipe, por meio da cooperação, da confiança e da união, que permitem a troca de experiência entre os trabalhadores e que possibilitem discutir coletivamente os problemas do setor, a fim de evitar possíveis conflitos.

Um estudo realizado com enfermeiros que trabalhavam no ambiente hospitalar encontrou resultado semelhante e identificou o predomínio de conflito de origem interpessoal entre a equipe de enfermagem. Sendo assim, a adoção de uma liderança participativa, baseada no diálogo, surge como estratégia para o enfrentamento dos conflitos. ${ }^{3}$

Quanto aos conflitos relacionados à tarefa, destaca-se a dificuldade de alguns profissionais em seguirem regras, normas, acordos e, até mesmo, a escala de trabalho:

nesse momento, a gente está passando por um grande conflito, que é uma funcionária. Acho que é o grande conflito das equipes é um se destacar por não querer trabalhar, um se destacar por não querer seguir as regras. Eu acho que esse é o pior conflito. Por exemplo, não chegar no horário, não conseguir fazer as coisas de acordo ou como os outros. (E2)

\section{o conflito maior é pela escala, eu acredito que é a folga. (E7)}

Conforme os relatos evidencia-se certa dificuldade de alguns profissionais em seguir as normas e regras estabelecidas pela instituição, o que pode contribuir para o aparecimento de conflitos e interferir no andamento do trabalho. Por outro lado, considera-se que as regras institucionais buscam organizar e facilitar o processo de trabalho dos enfermeiros e demais profissionais da saúde. No entanto, defende-se a importância da participação dos trabalhadores nos processos decisórios, para que se sintam valorizados e corresponsáveis pelas decisões e pela implementação das ações, principalmente relacionadas ao cuidado.

As relações hierarquizadas são reais quando determinados profissionais adotam uma postura autoritária perante a equipe. Todavia, essa imagem autocrática precisa ser desconstruída para que se possa construir novas relações de trabalho na saúde e na enfermagem. ${ }^{20} \mathrm{O}$ estabelecimento de relações pautadas no autoritarismo tende a ser frágil e seu alicerce principal é o medo.

Os conflitos de tarefa provém da percepção de desacordo entre membros de um grupo sobre o conteúdo de suas decisões, podendo envolver diferenças entre pontos de vista, ideias e opiniões. ${ }^{21}$ Fato que é representado no depoimento do entrevistado E2, quando menciona o não cumprimento das tarefas a serem realizadas por um outro profissional.

Frente ao exposto, salienta-se que situações conflitantes costumam gerar frustrações e discordâncias, tornando o ambiente desagradável. Entretanto, podem ter valor positivo quando são utilizados como impulsionadores do crescimento pessoal e organizacional, bem como da produtividade, funcionando como um fator desencadeante de mudanças pessoais e coletivas. ${ }^{20}$

Os resultados também sinalizam para a existência de conflitos relacionados ao processo administrativo, que se referem à maneira como a atividade laboral é realizada. 


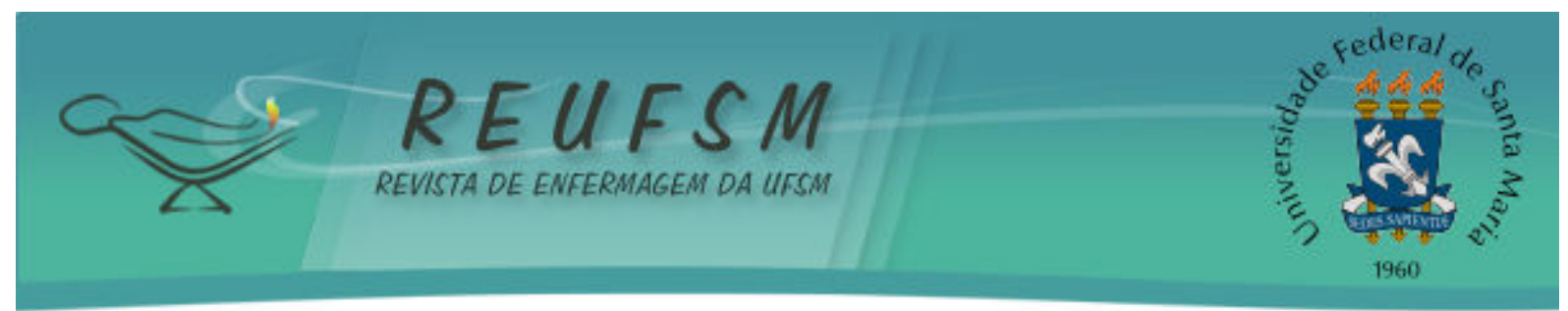

Para os entrevistados estes refletem problemas na organização do serviço, assim como a questão salarial.

Os conflitos que existem são mais em relação à mudança de administração da instituição. Hoje a gente tem a possibilidade da entrada de uma empresa para administrar o hospital. (E5)

Conflitos que a gente tem aqui dentro da instituição, porque o funcionário trabalha muito mais e recebe muito menos. (E4)

Nota-se que a ferramenta gerencial denuncia processos silenciosos que ocorrem no ambiente de trabalho e que revelam interesses, desejos e autoritarismo. ${ }^{19}$ Salienta-se que os conflitos sempre surgirão em toda e qualquer organização de serviço e a melhor maneira de resolvê-los é por meio da negociação, em que todos os interesses sejam levados em consideração para haver um acordo aceitável. ${ }^{22}$

Apesar disso, foi possível identificar estratégias utilizadas pelos enfermeiros para o enfrentamento dos conflitos. Dentre elas, primeiramente destaca-se o diálogo, sendo evidenciado por meio dos seguintes depoimentos:

conversando, dialogando, chamando atenção quando é necessário. (E1)

conversando, sentando frente a frente, sempre com diálogo, essa é a forma que eu uso. (E2)

a gente vai conversar, ver o que aconteceu e vai chegar em um resultado que seja o melhor para a equipe, para a unidade e para $o$ paciente. (E10)

Conforme apresentado nos relatos, os entrevistados dispõem de algumas estratégias para enfrentar essas situações. Dentre elas, percebe-se a valorização e a importância do diálogo nas relações entre os profissionais, de forma que possibilite o entendimento e a satisfação de todos.

Resultado semelhante foi evidenciado em um estudo realizado com enfermeiros, em que as principais estratégias gerenciais utilizadas na intercessão dos conflitos envolveram posturas menos autoritárias, como a participação dos membros da equipe, bem como o diálogo e a escuta das necessidades individuais dos trabalhadores. Destaca-se, ainda, que adotar a imparcialidade e ter cautela no manejo das situações são atitudes relevantes na tomada de decisões. ${ }^{23}$

Nesse contexto, é possível afirmar que as pessoas constroem uma rede de comunicação com vistas a harmonizar as relações na busca por uma convivência saudável, que traz benefícios para todos. A partir do estabelecimento de uma boa comunicação, pode-se obter, conforme os vínculos criados, relações de ajuda entre os profissionais.

Entende-se que o modelo de liderança dialógica é um instrumento gerencial baseado no estabelecimento de um processo de comunicação eficaz e que é capaz de instigar a valorização, a autonomia e a corresponsabilização individual dos membros da equipe de enfermagem. ${ }^{5} \mathrm{~A}$ partir do estabelecimento de relações pautadas no diálogo, acredita-se que o enfermeiro poderá gerenciar de forma mais construtiva os conflitos dos serviços de saúde. Este diálogo consiste em uma comunicação que valoriza os 


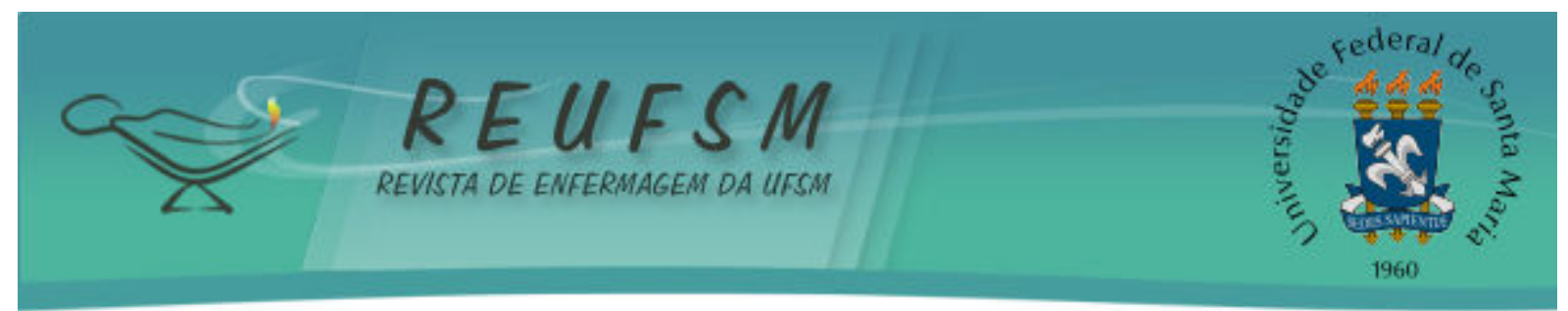

conhecimentos prévios dos sujeitos, enquanto seres históricos e sociais, profissionais que defendem suas convicções, com coerência entre suas ações e seus discursos. ${ }^{3}$

Além do diálogo, evidenciou-se a realização de reuniões de equipe como estratégia para gerenciar os conflitos. Essa estratégia pode ser implementada no ambiente de trabalho, com o intuito de aproximar o enfermeiro e seus colaboradores, a fim de que possam expor suas opiniões e dirimir dúvidas.

Reunião seria uma estratégia, conversar, diálogo, tentar ser clara, não deixar as coisas no ar, deixar todos os pontos esclarecidos, não [deixar] pairar dúvidas. Mas eu acho que a minha principal arma, eu acho que é a reunião. (E7)

Conforme o depoimento, identificou-se que a reunião é utilizada como estratégia para compartilhar informações quanto à estruturação e organização do trabalho, o que pode colaborar para a qualificação da assistência prestada. Dessa forma, ressalta-se a importância das reuniões no trabalho da equipe de enfermagem, para que o enfermeiro implemente mudanças e, por meio delas, divida ideias e informações, a fim de desenvolver habilidades e promover maturidade nos integrantes da equipe, compartilhando das decisões relativas à prática profissional.

\section{CONSIDERAÇÕES FINAIS}

Mediante o desenvolvimento do presente estudo, buscou-se conhecer a percepção de enfermeiros-líderes sobre o gerenciamento de conflitos no ambiente hospitalar. Constatou-se que os conflitos estão presentes diariamente no trabalho dos enfermeiros e o exercício da liderança poderá facilitar seu enfrentamento.

Por meio dos resultados, foi possível identificar que os profissionais percebem dificuldades para liderar e gerenciar os conflitos no ambiente hospitalar. Também foi possível identificar fragilidades no ensino destas competências profissionais durante a graduação, o que aponta para a importância de abordar, na graduação, o gerenciamento de conflitos de maneira transversal, visando auxiliar no ensino, de modo a facilitar o seu exercício nos serviços de saúde.

Os conflitos de relacionamento, na percepção dos enfermeiros-líderes, predominaram no ambiente hospitalar e foram causados, principalmente, pela falta de continuidade das atividades entre as equipes de enfermagem e o excesso de trabalho. Além disso, as estratégias utilizadas para minimizar os conflitos foram diálogo e realização de reuniões de equipe, as quais estão interligadas, pois, em conjunto, fortalecem o trabalho do enfermeiro e a qualidade da assistência.

A utilização de entrevistas como única técnica de coleta de dados pode ser considerada uma limitação do estudo, visto que não foi possível observar, na prática, a atuação do enfermeiro gerenciando os conflitos e as estratégias adotadas para solucionálos. Para isso, recomenda-se o desenvolvimento de investigações envolvendo outras técnicas de coleta de dados, tais como observação e grupo focal, em trabalhos sobre a temática, com vistas a contribuir para o fortalecimento da atuação do enfermeiro-líder no gerenciamento de conflitos. Além de estudos que busquem englobar os profissionais da equipe, com o intuito de conhecer seu entendimento sobre a liderança do enfermeiro e ampliar os olhares diante do objeto estudado. 


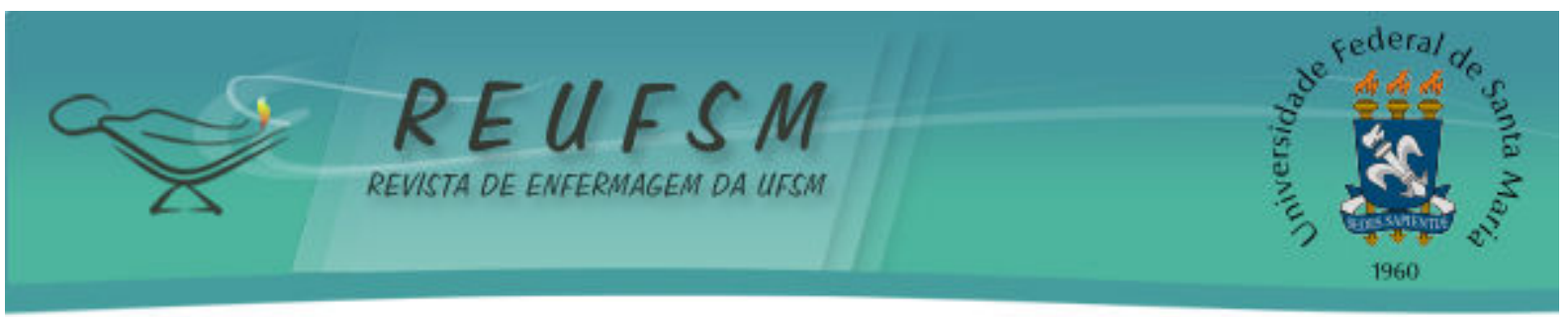

\section{REFERÊNCIAS}

1. Prochnow AG, Leite JL, Erdmann AL, Trevisan MA. O conflito como realidade e desafio cultural no exercício da gerência do enfermeiro. Rev Esc Enferm USP [Internet]. 2007 [acesso em 2015 abr 5];41(4):542-50. Disponível em: http://www.scielo.br/pdf/reeusp/v41n4/01.pdf.

2. Wagner LR, Thofehrn MB, Amestoy SC, Porto AR, Arrieira ICO. Relações interpessoais no trabalho: percepção de técnicos e auxiliares de enfermagem. Cogitare Enferm [Internet]. 2009 [acesso em 2015 abr 5];14(1):107-13. Disponível em: http://ojs.c3sl.ufpr.br/ojs/index.php/cogitare/article/view/14123.

3. Amestoy SC, Backes VMS, Thofehrn MB, Martini JG, Meirelles BHS, Trindade LL. Gerenciamento de conflitos: desafios vivenciados pelos enfermeiros-líderes no ambiente hospitalar. Rev Gaúch Enferm [Internet]. 2014 [acesso em 2015 abr 6];35(2):79-85. Disponível em: http://seer.ufrgs.br/index.php/RevistaGauchadeEnfermagem/article/view/40155.

4. Barranco E, Moreira MC, Menezes MFB. O líder de enfermagem em unidades oncológicas: intervenções da subjetividade na organização de espaços saudáveis. Rev Bras Cancerol [Internet]. 2009 [acesso em 2015 abr 7];52(2):213-8. Disponível em: http://www.inca.gov.br/rbc/n_56/v02/pdf/06_artigo_lider_enfermagem_oncologicas.pdf.

5. Amestoy SC, Trindade LL, Waterkemper E, Heidman ITS, Boehs AE, Backes VMS. Liderança dialógica nas instituições hospitalares. Rev Bras Enferm [Internet]. 2010 [acesso em 2015 abr 7];63(5):844-7. Disponível http://www.scielo.br/pdf/reben/v63n5/25.pdf.

6. Vendemiatti $M$, Siqueira ES, Filardi F, Binotto B, Simioni F. Conflito na gestão hospitalar: o papel da liderança. Ciênc Saúde Coletiva [Internet]. 2010 [acesso em 2015 abr 7];15 Supl 1:1301-14. Disponível em: http://www.scielo.br/pdf/csc/v15s1/039.pdf.

7. Guerra ST, Prochnow AG, Trevisan MA, Guido LA. O conflito no exercício gerencial do enfermeiro no âmbito hospitalar. Rev Latinoam Enferm [Internet]. 2011 [acesso em 2015 abr 8];19(2):362-9. Disponível em: http://www.scielo.br/pdf/rlae/v19n2/pt_19.pdf.

8. Robbins SP, Judge TA, Sobral FP. Comportamento organizacional: teoria e prática no contexto brasileiro. 14 ed. São Paulo: Pearson Education; 2011.

9. Oliveira AM, Lemes AM, Machado CR, Silva FL, Miranda FS. Relação entre enfermeiros e médicos em hospital escola: a perspectiva dos médicos. Rev Bras Saúde Mater Infant [Internet]. 2010 [acesso em 2015 abr 8];10 Supl 2:433-9. Disponível em: http://www.scielo.br/scielo.php?script=sci_arttext\&pid=S1519-38292010000600023.

10. Deslandes SF. O projeto de pesquisa como exercício científico e artesanato intelectual. In: Minayo, MCS, Deslandes SF; Gomes R. Pesquisa social: teoria, método e criatividade. $27^{\mathrm{a}}$ ed. São Paulo: Hucitec; 2008. p. 31-60.

11. Minayo MCS. O desafio do conhecimento: pesquisa qualitativa em saúde. $12^{\mathrm{a}}$ ed. São Paulo: Editora Hucitec/Rio de Janeiro: ABRASCO; 2010.

12. Brasil. Ministério da Saúde. Conselho Nacional de Saúde. Resolução CNS n 466, de 12 de dezembro de 2012. Aprova diretrizes e normas regulamentadoras de pesquisas envolvendo seres humanos. Brasília: Conselho Nacional de Saúde; 2012.

13. Benetti ERR, Kirchhof RS, Guido LA, Prochnow AG, Lima SBS, Weiller TH, et al. 0 conflito na atividade gerencial do enfermeiro. Rev Contexto Saúde [Internet]. 2013 [acesso 


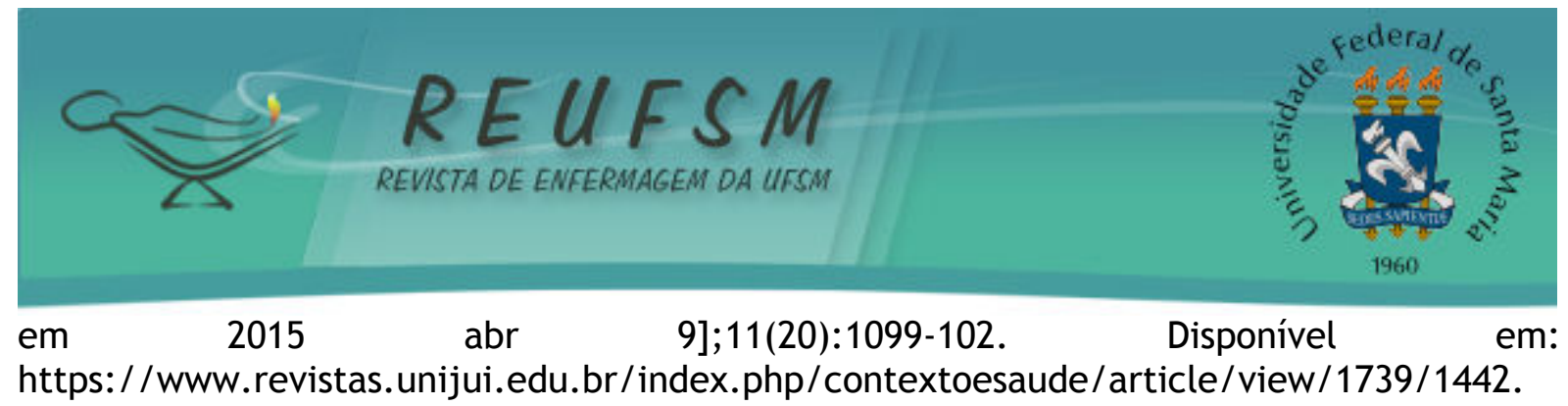

14. Lampert AN, kinalski DF, Machado BP, Lima SBS. Conflitos gerenciais: dificuldades para o enfermeiro gerente. Rev Enferm Atenção Saúde [Internet]. 2013 [acesso em 2015 abr 8];2(3):96-105. Disponível

em:

http://www.uftm.edu.br/revistaeletronica/index.php/enfer/article/view/622.

15. Cardoso MLAP, Ramos LH, D'Innocenzo M. Liderança Coaching: um modelo de referência para o exercício do enfermeiro-líder no contexto hospitalar. Rev Esc Enferm USP [Internet]. 2011 [acesso em 2015 abr 8];45(3):730-7. Disponível em: http://www.scielo.br/pdf/reeusp/v45n3/v45n3a26.pdf.

16. Mattosinho MMS, Coelho MS, Meirelles BHS, Souza SS, Argenta CE. Mundo do trabalho: alguns aspectos vivenciados pelos profissionais recém-formados em enfermagem. Acta Paul Enferm [Internet]. 2010 [acesso em 2015 abr 9];23(4):466-72. Disponível em: http: / / www.scielo.br/scielo.php?script=sci_arttext\&pid=S0103-21002010000400004.

17. Amestoy SC. Percepção dos enfermeiros sobre o processo de ensino-aprendizagem da liderança. Texto \& Contexto Enferm [Internet]. 2013 [acesso em 2015 abr 9];22(2):468-75. Disponível em: http://www.scielo.br/scielo.php?script=sci_arttext\&pid=S0104-07072013000200024.

18. Spagnol CA, Monteiro LAS, Paula CL, Bastos JM, Honorato JAG. Vivenciando situações de conflito no contexto da enfermagem: o esquete como estratégia de ensinoaprendizagem. Esc Anna Nery Rev Enferm [Internet]. 2013 [acesso em 2015 abr 9];17(1):184-9. Disponível em: http://www.scielo.br/pdf/ean/v17n1/26.pdf.

19. Dignam D, Duffield C, Stasa H, Gray J, Jackson D, Daly J. Management and leadership in nursing: an Australian educational perspective. J Nurs Manag. 2012;20(1):65-71.

20. Spagnol CA, Santiago GR, Campos BMO, Badaró MTM, Vieira JS, Silveira APO. Situações de conflito vivenciadas no contexto hospitalar: a visão dos técnicos e auxiliares de enfermagem. Rev Esc Enferm USP [Internet]. 2010 [acesso em 2015 maio 5];44(3):803-11. Disponível em: http://www.scielo.br/scielo.php?script=sci_arttext\&pid=S0080-62342010000300036.

21. Costa DT, Martins MCF. Estresse em profissionais de enfermagem: impacto do conflito no grupo e do poder do médico. Rev Esc Enferm USP [Internet]. 2011 [acesso em 2015 maio 4];45(5):1191-8. Disponível em: http://www.scielo.br/pdf/reeusp/v45n5/v45n5a23.pdf.

22. Sales AAR, Lima FRF, Farias FSAB. Refletindo sobre a administração e negociação de conflitos nas equipes de saúde. Rev Bras Promoç Saúde [Internet]. 2007 [acesso em 2015 maio 7];20(2):111-5. Disponível em: http://ojs.unifor.br/index.php/RBPS/article/view/1011.

23. Lima SBS, Rabenschlag LA, Tonini TFF, Menezes FL, Lampert AN. Conflitos gerenciais e estratégias de resolução pelos enfermeiros gerentes. Rev Enferm UFSM [Internet]. 2014 [acesso em 2015 jun 6];4(2):419-28. Disponível em: http://periodicos.ufsm.br/reufsm/article/view/11888/pdf.

Data de recebimento: $28 / 05 / 2015$

Data de aceite: 04/05/2016

Contato do autor responsável: Simone Coelho Amestoy

Endereço postal: Rua Dr. Augusto Viana, s/n. Bairro: Canela, CEP: 40110-060, Salvador, Bahia

E-mail: simoneamestoy@hotmail.com 